\title{
The Global War Against the Novel Coronavirus Enemy: What Is COVID-19? Of Course, Nothing Is Certain Yet
}

\author{
Elham F. Mohamed (Corresponding author) \\ Air Pollution Department, Environmental Research Division, National Research Centre \\ 33 EL Bohouth St., Dokki, Giza, P.O.12622, Egypt \\ E-mail: elham_farouk0000@yahoo.com
}

\begin{abstract}
Gamal Awad
Chemistry of Natural and Microbial Products Department, Pharmaceutical and Drug Industries Research Division, National Research Centre

33 EL Bohouth St., Dokki, Giza, P.O.12622, Egypt

E-mail: awad_gamal7@yahoo.fr
\end{abstract}

Received: September 13, 2020 Accepted: November 10, 2020 Published: November 24, 2020

Doi: 10.5296/jab.v8i2.18002 URL: https://doi.org/10.5296/jab.v8i2.18002

\begin{abstract}
In this review, the new Coronavirus (COVID-19) pandemic problem was discussed. This concept was covered via answer the comment questions about the new COVID-19 problems. The main objective of this review is to supply a comprehensive knowledge in the definition of COVID-19, Corona virus concept, discusses the infection common symptoms, the transmission, diagnosis, and management of COVID-19. Finally, we provide a tool and recommendations to avoid infection spread. In this review, we collected data from diverse research reports such as the World Health Organization (WHO), guidelines and other articles. Because of the wide and fast spread of the virus, academic researchers, environmental scientists, antiviral designs, vaccine development against the virus and providers of health care are expected to acquire current information and future outlooks of the new pandemic coronavirus.
\end{abstract}

Keywords: COVID-19, Pandemic, Symptoms, Diagnosis, Management and recommendations 


\section{Macrothink}

\section{What Is COVID-19?}

Before going into the details of this emerging pandemic, we must first define this term that has imposed itself robustly on the world. We will give a simplified and comprehensive image about the definition of this pandemic to remove any confusion of information for the normal reader as well as the specialized reader.

COVID-19 definition: firstly, the COVID-19 concept was defined by WHO: it is the acronym derived from Coronavirus (COV) disease 2019. It is a new emergent Coronavirus causing a respiratory tract infection. This new Coronavirus strain is not formerly identified in humans. This virus named severe acute respiratory syndrome Coronavirus 2 (SARS-CoV-2; previously called 2019-nCoV) (Gorbalenya et al., 2020). Furthermore, the majority of coronaviruses provokes diseases ranged from the usual cold to acute ones (Abdi, 2020).

Among the important terms that must be clarified in this section are zoonotic that is transmitted from animals to human, lastly, they have the ability to transmit from human to human (Ye et al., 2020). Therefore, diverse types of these viruses have been well known for several years, but the problem is that COVID-19 is a new kind virus that has not been identified previously; furthermore, this new virus is rapidly spreading, highly contagious and constantly evolves in the human population.

\section{Where and When did the Coronavirus Epidemic Start?}

The first COVID-19 cases took place in human in Wuhan City, Hubei Province, China, in December 2019 (Lu et al., 2020), the virus has incubated for four months and thereafter spread as a global epidemic. In January 2020, the WHO announced the COVID-19 as a global epidemic for health (Wang et al., 2020). It declared COVID-19 as a global pandemic on March 2020, when more than 3.5 million cases of COVID-19 were confirmed (WHO, 2020a; Rodriguez-Morales et al., 2020). There were almost 10 million COVID-19 confirmed cases and 5 million deaths by the end of June 2020, and an increase in the number of positive cases and deaths is still continued, which menaces the human health and economic (Lu et al., 2020).

\section{What Is the Structure of Coronaviruses?}

COVID viruses are teeny infections (65-125nm in width) having a crown-like appearance under the electron magnifying microscope, owing to the existence of spike glycoproteins on the envelope (Rodriguez-Morales et al., 2020; Lu et al., 2020; Xu et al., 2020; Shereen et al., 2020). Covids have enormous (26-32 kbs) single deserted and positive sense RNA genomes. The genome is a part of 14 open edges, which combine 16 nonstructural proteins and four main basic proteins (Wu et al., 2020; Chen et al., 2020; Pillaiyar et al., 2020). In Figure 1; (1) Spike protein (S), this is a protein divided into two subunits (S1 and S2), S1 includes the receptor binding domain (RBD), and linked with a viral passage into host cells, (2) Membrane protein (M), (3) Envelope protein (E), and (4) Nucleocapsid protein $(\mathrm{N})$. 


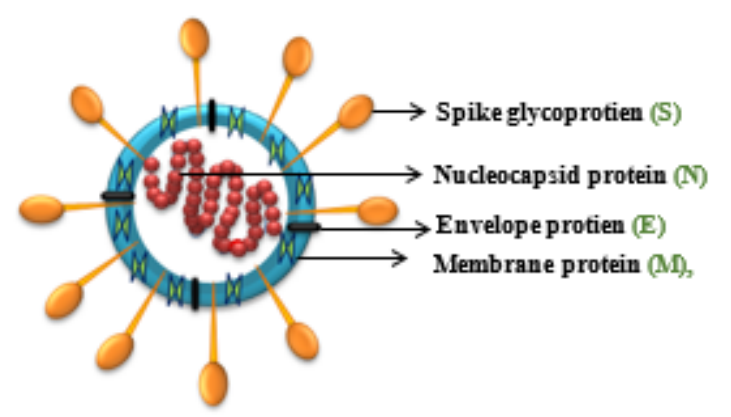

Figure 1. Illustration of the Coronavirus structure

\section{What Are the Potential Origins of COVID-19 virus?}

The new coronavirus started from the live animal market at Wuhan, South China, where bats, raccoon dogs, snakes and other animals are sold, and rapidly spread up to all countries (Wang et al., 2020). The novel SARS-CoV-2 virus is believed to possess a zoonotic origin and to result from a cross-species transmission. Moreover, the genome sequencing investigated that the novel virus (SARS-CoV-2) is typically identical to a bat coronavirus (Bat CoV RaTG13) (Lu et al., 2020; Li et al., 2020; Zhou et al., 2020). This indicates that the bat CoV and human SARS-CoV-2 might have the same primogenitor, and that bats are a possible incubator for the virus (Fan et al., 2019; Zhang et al., 2020). However, the epidemiological reason of the initial infected human group in Wuhan City (Hubei, China) was a wholesale fish and the live animal market, and that bats were not available for sale. Pangolin, snakes, turtles and several wild mammals such as cats and dogs have been identified as possible intermediate hosts based on the predicted interaction between the spike protein of SARS-CoV- 2 and host (Zhao et al., 2020; Liu et al., 2020). Nevertheless, more direct evidence is required to clarify the arguments.

\section{What Are the Transferring Ways of Virus COVID-19?}

The droplet size of the virus plays a significant role to transfer the infections; particles with diameter $>5-10 \mu \mathrm{m}$ are indicated to the respiratory droplets; and the particles with diameter $<5 \mu \mathrm{m}$ are referred to the droplet nuclei.

Transmission of the respiratory droplet is the main route, which transferred via the contact from person to another by asymptomatic carriers (Zou et al., 2020; Gao et al., 2020). At the beginning of the virus, a large number of COVID-19 cases $(75,465)$ were analyzed in China and its transmission in the air was not cited (Paho, 2020; CDC, 2020). Today, the airborne transmission of COVID-19 has been confirmed in several works. At present, COVID-19 is usually transmitted between people by the respiratory droplets and/or by direct or indirect contact. Droplet transmission occurs when a person was in direct contact (almost $1 \mathrm{~m}$ ) with an infected person (coughs or sneezes) (Dhand and Li, 2020). Transmission may occur by droplets that land on the surfaces and equipments, and environment around the infected person. These droplets are then transferred when someone touches the infected surface.

Consequently, COVID-19 transmission can occur by direct or indirect contact with an infected person or contaminated surface (Figure 2). Till now, there is lack of publication reported on whether the COVID-19 virus can be determined in the air. The transmission in air 


\section{Ml Macrothink}

refers to the microbe existence within droplet nuclei of diameter particles $<5 \mu \mathrm{m}$ remaining in the air for long times and it can transmit to others over distances $>1 \mathrm{~m}$ (Ong et al., 2020). A recent publication in the New England Journal of Medicine reported that the presence of COVID-19 in aerosol particles stayed up to 3 hours under controlled conditions (VanDoremalen et al., 2020). These initial findings need to be interpreted carefully; here some reports revealed no RNA detection of COVID-19 in the air samples (Cheng et al., 2020; Ong et al., 2020). WHO is aware of other reports, which confirmed the RNA existence of COVID-19 in the air, but not yet cited in peer-reviewed journals. It is important to indicate that the detection of RNA in environmental samples and PCR-based methods are not indicators of the viable virus, which could be transferred. Further studies are required to evaluate whether it is a possibility for COVID-19 detection in the air samples from the rooms of patients, where no ways to liberate aerosols are occurring. Hence, it is useful to know whether the viable virus is present and what is the role of its transmission. In addition, there are some reports found that COVID-19 may provoke an infection of intestine and be present in faeces. Current information on its potential transmission by faecal ways is briefly cited and the possible implications are discussed from a public health (Amirian, 2020). To date, there are no reports on the transferring of the virus via faeces/oral.

Here, we should give attention to the following points based on the recent publications; WHO continues to recommend precautions against the droplet and contact for those caring people for COVID-19 patients, WHO continues to recommend airborne precautions for the conditions and environment in which aerosol generated and supportive treatment are performed according to the risk. These recommendations are coincided with other national and international guidelines, developed by the European Society of Intensive Care Medicine and Society of Critical Care Medicine, Australia, Canada, and UK, and finally WHO carefully records obvious evidences about this virus and updates this scientific brief as available information.

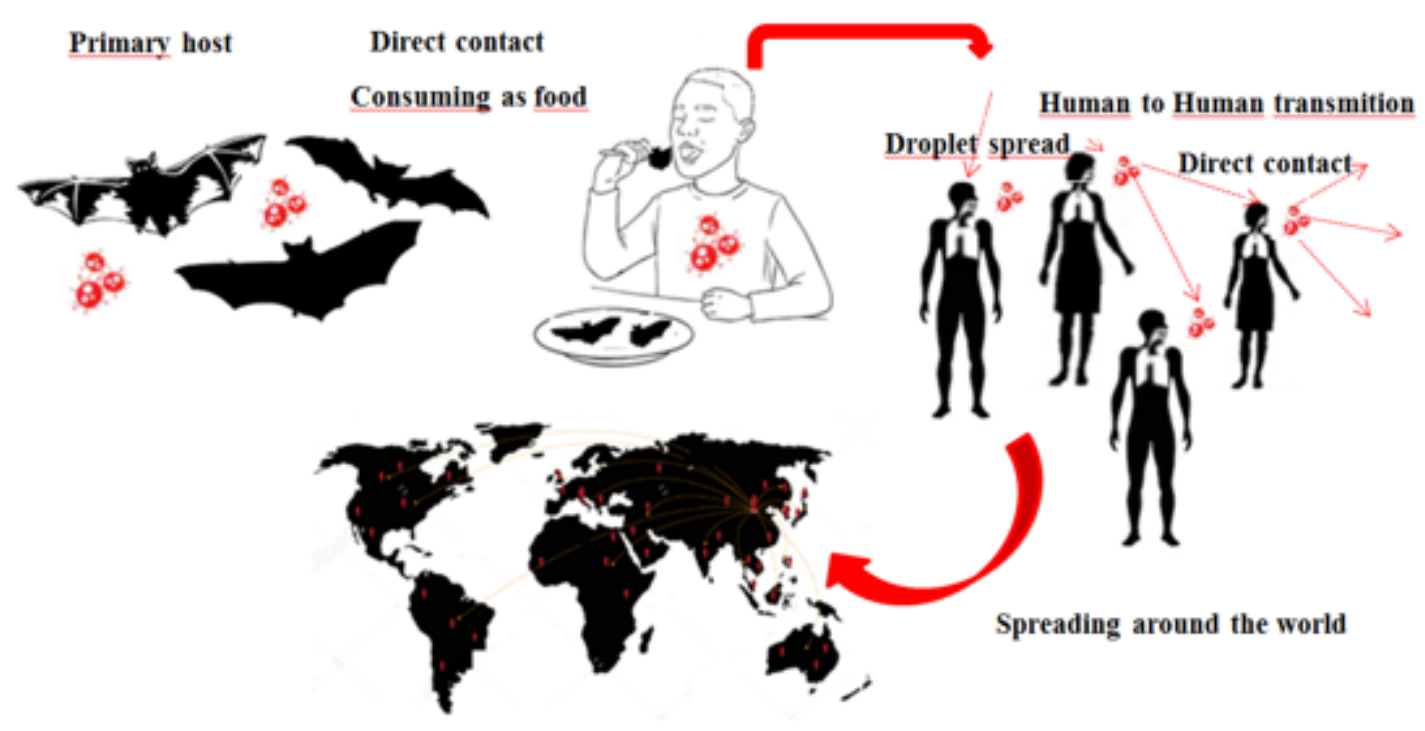

Figure 2. Illustration of potential origin and the transmission modes of COVID-19 virus 


\section{What Are the COVID-19 Symptoms?}

Clinically, we were not able to differentiate between COVID-19 and the usual viral respiratory symptoms, as they share the general symptoms, including: sore throat, headaches, cough, fatigue, rhinorrhea and dyspnea. Additionally, symptoms of gastrointestinal (like, diarrhea and nausea) were also cited (Pathak, 2020; WHO, 2020b; Liu et al., 2020). Less common symptoms are found such as pains and aches, loss of taste or smell, conjunctivitis, a rash on the skin, or de-coloration of fingers or toes. These symptoms have ranged from mild $(81 \%)$, severe (14\%), to critical (5\%) and the rate of mortality is around $2 \%$ of the confirmed COVID-19 (Temgoua et al., 2020; Di Gennaro et al., 2020). The speed of symptoms is graduated from bad to worse day by day. However, it's difficult to notice the symptoms in the first days of infection. This is usually observed after 5-6 days; a day-by-day breakdown of COVID-19 symptoms is illustrated in Figure 3 (WHO, 2020b; Bendix, 2020).

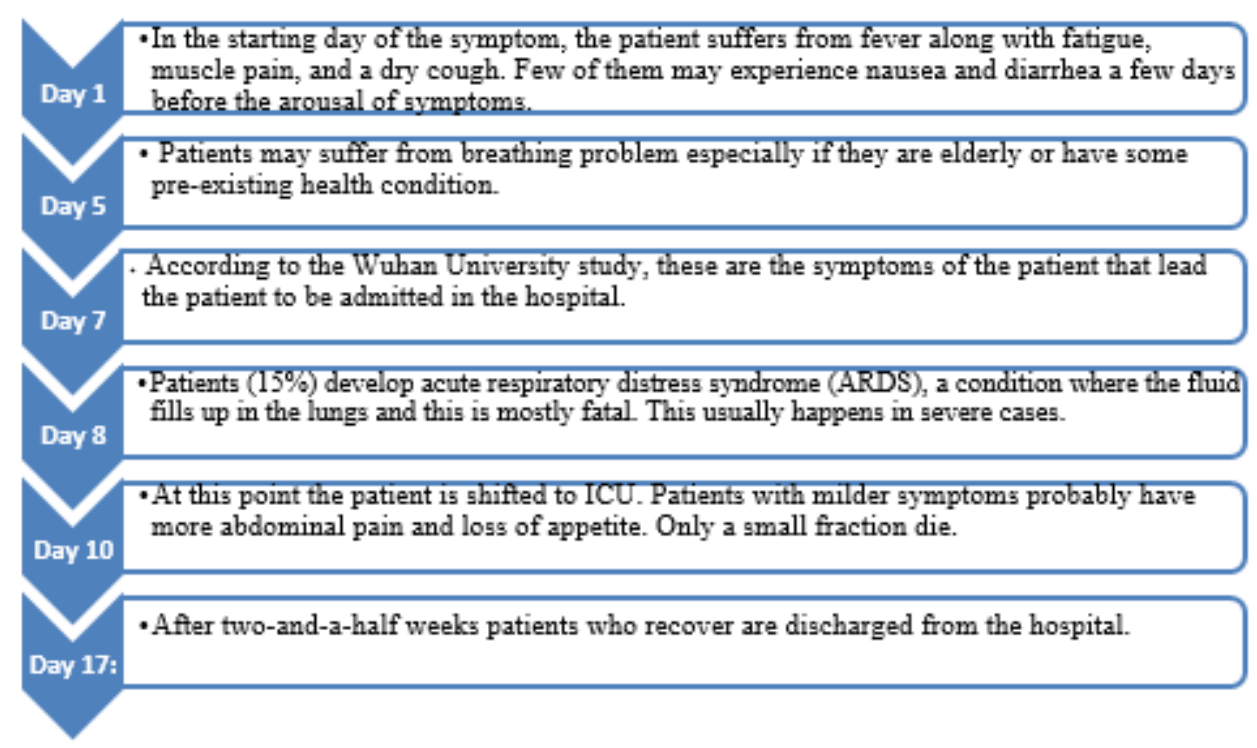

Figure3. Diagram illustrates the speed of COVID-19 symptoms for an infected patient evolved from bad to worse day by day

\section{What Is the Diagnostic Approach of COVID-19?}

As coronavirus is globally widespread, clinicians should have a low threshold for COVID-19 suspicion, and the probability is highly augmented if the patient stayed or traveled through the first 14 days to a region contaminated by severe COVID-19, or he has a direct contact with a confirmed or suspected case (WHO, 2020b).

COVID-19 diagnosis depends upon the combination of epidemiological criteria, clinical imaging based tests and the existence of clinical symptoms, besides laboratory assay tests (DNA). Comparative sensitivity and specificity of these factors need to be carefully estimated, when more data is available. Moreover, in several cases the combination of these tests is required to improve the diagnostic accuracy of COVID-19. Primarily, the patient with COVID-19 is possibly considered to be suffering from fever and/or cough and dyspnea. It has 
also severe lower respiratory tract symptoms without any clear reason. Other obvious symptoms include smell or taste disorders, diarrhea, and myalgias. Testing strategies include the following diagnostic techniques:

1) Sputum, throat swabs, and lower respiratory secretion samples are taken for determining RT-PCR of COVID-19. In patients with positive COVID-19, the count of white blood cells was varied. Leukopenia, lymphopenia, and leukocytosis were recorded, although lymphopenia appeared more abundant (Lippi et al., 2020; Lagier et al., 2020). The levels of ferritin and lactate dehydrogenase were elevated and high aminotransferase levels were also reported ( $\underline{\mathrm{Di}}$ Gennaro et al., 2020). Many patients with pneumonia have normal procalcitonin levels in the blood serum. High levels of D-dimer and lymphopenia are usually related to the mortality. The RT-PCR negative results do not mean that there is no infection by COVID-19 and should not be considered as the sole decision, but a combination of patient history, clinical observations, and epidemiological knowledge must be included. Indeed, many factors lead to negative results for an infected patient, such as poor specimen quality, late or very early collection, and poor handling/shipping, besides technical causes interfering with the test, like the virus PCR mutation or inhibition. Consequently, with a negative result, retesting is recommended after 48 hours.

2) Another used diagnostic test in COVID-19 is the lung computed tomography (CT): The CT image in patients with COVID-19 mainly demonstrates abnormal glass opacification sites, confirming the presence of the viral pneumonia. Other studies have suggested that the abnormalities of chest $\mathrm{CT}$ are bi-lateral having a peripheral distribution, and involving low lobes (Ai et al., 2020; Li and Xia, 2020). Chest CT may be helpful using the lung CT, and the sensitivity of nasopharyngeal swab may be in the range of 60-70\% (Ai et al., 2020). Lung CT is highly sensitive to the hospitalized patients with COVID-19 confirmed by a positive RT-PCR. With a population of 1014 patients taken from January 06 to February 06, 2020 (Tongji Hospital, Wuhan, China), using RT-PCR as a reference, the lung CT image sensitivity for COVID-19 was 97\%. Importantly, high percentage (60-93\%) of patients had initial positive lung CT, coincided with COVID-19 before the initial test of positive RT-PCR (Ai et al., 2020).

3) Another important tool also used is the viral tests and Nucleic acid shedding, although $42 \%$ of patients showed an improvement of lung CT before recording RT-PCR negative results (Ai et al., 2020). However, it is important to notice that DNA shedding does not usually show the existence of live virus (Tahamtan and Ardebili, 2020). Moreover, the viral test informs you if you possess a current infection. Samples of viral tests taken from the respiratory system (like nose swabs) confirmed the infection by COVID-19 (Ong et al., 2020).

4) An antibody test: After human infected by COVID-19, the antibodies can be produced within 5-7 days, while antibodies can be obtained within 10-15 days and probably stay detected for months or years (Zhou et al., 2020). Moreover, the antibody test may not be detected if you have early infections, because it can take 1-3 weeks after infection to obtain antibodies. A positive test result confirms that antibodies are obtained due to an infection with COVID-19. Experience with other viruses indicates that antibodies may offer protection from future infections. However, the study is ongoing to determine if these antibodies to COVID-19 can protect someone from the infection with the virus again, and how long that 
protection might stay. A negative test result means that there are no detectable antibodies found in the specimen. More research is ongoing to find out if antibodies can make people immune to the virus.

The Biosafety precaution and laboratory diagnosis protection of clinical specimens from patients of the suspected or confirmed COVID-19 should be conducted adopting practices and procedures described by WHO (WHO, 2020c).

In several cases, since the availability of testing for COVID-19 is not accessible, the COVID-19 diagnosis is made theoretically based on a compatible clinical presentation in an exposed site, especially when no other symptom cause is evident. It is acceptable to assume that the patient had COVID-19 and advise him to self-isolate at home (if hospitalization is not warranted) and alert the clinician about worsening symptoms (WHO, 2020d).

\section{What Are the Most Biosafety Precautions and Protections?}

Actually, the COVID-19 virus is primarily transmitted between people via respiratory droplets and contact (WHO, 2020e; Pandey et al., 2020; Yang et al., 2020). The droplets can also be transferred directly to the individual next to the infected one. Thus, Biosecurity and personal protection can help in the control and prevention of the virus infection. The best way for virus protection is to avoid the exposure to the virus. We can summarize the Biosafety precautions and protections in the following points:

1) Performing hand hygiene frequently with alcohol or soap and water.

2) Avoid the touch of eyes, mouth and nose.

3) Keeping a distance (at least $1 \mathrm{~m}$ ) required to avoid the infection from individuals.

4) Using personal protective equipments (PPE) can protect people from infection. The recommended PPE (WHO) includes medical masks, gowns, gloves, goggles or a face shield, aprons and respirators (Pandey et al., 2020).

\section{Are There Treatments for COVID-19?}

Actually, there are no drugs approved for COVID-19 by the Food and Drug Administration. However, several drugs were approved for other indications, besides multiple agents are currently studying for the COVID-19 treatment in the clinical trials around the world (Wang et al., 2020). Moreover, providers can investigate drugs or agents that are approved or licensed for other indications through different mechanisms for COVID-19; providers include Emergency Use Authorizations (EUAs), Emergency Investigational New Drug (EIND) applications, and use programs with drug manufacturers, and/or off-label use. At present, the Panel recommends unapproved or promising COVID-19 treatments to be investigated in controlled clinical trials. Several data and publications from randomized controlled trials and observational groups are rapidly emerging, some in peer-reviewed journals, others as unpublished manuscripts, and some cases in press statements. These data sources and the Panel experiences are used to determine whether new recommendations are secured. Finally, the choice of these data depends on the patient and the provider that define the decision. 


\section{Are There Human Vaccines Currently Available for Covid-19?}

Actually, no human vaccine is ready for Covid-19, but development of nearly 120 vaccines is carried out. Techniques include the use of nucleic acids (RNA or DNA), live or inactivated virus, viral vectors, and recombinant proteins (Pandey et al., 2020; Adhikari et al., 2020).

Challenges to create an effective vaccine consisted of barriers (e.g., whether $\mathrm{S}$ or receptor binding domain proteins provoke more protective antibodies), possibility of large scale production (e.g., including effectiveness and safety), and legal ways (e.g., transfer of technology and license approvals). The SARS-CoV-2 S seems to be a protective promising immunogenic protein, but the protein full length or the receptor-binding domain, which is sufficient to prevent transmission, stays obscure. Other factors include the number of vaccine doses required to give long immunity. Nowadays, more than ten Covid-19 vaccines are actually being tested in the last phase trial and predicted to be produced in large scale in the January 2021. Lastly, Pfizer and BioNTech Companies, USA-Germany announced in November 9, 2020 that a novel vaccine for COVID-19 is produced with an efficiency reached to $90 \%$. In this study, the results found that individuals who taken two vaccine injections with three weeks having more than $90 \%$ fewer cases of symptomatic Covid-19 than those with placebo (Pfizer, 2020). Other prevention approaches will emerge in the next months, which include monoclonal antibodies, convalscenttiter, and hyper immune globulin. These approaches will be utilized in high risk persons, such as health care workers and older adults.

\section{Conclusions}

Pandemic COVID-19 provoked markedly increase in hospitalizations for pneumonia accompanied with multi-organ diseases. As of November 1, 2020, more than 50 million people around the world were infected by COVID-19 and more than 1 million was died. Many routes of transferring, infection, and treatment stay vague. Advanced prevention and effective control of COVID-19 will require clinical investigations.

At present, the number of confirmed cases of COVID-19 continues to augment, and various prevention and control measures continue to be needed. With more research on COVID-19, systematic treatment plans and guidelines have been improved, so it is most important for patients to be early diagnosed and admitted to the hospital for isolation. Asymptomatic patients with COVID-19 infection are unfortunately a silent infection source, which can render others at risk for infection without unknowing. Consequently, as more research is performed to interpret the mechanisms of COVID-19 infection and to create treatment methods, efforts to prevent its transmission by asymptomatic individuals will be the key to reduce its spread. While the epidemics of SARS, MERS and COVID-19, were all provoked by coronaviruses and shared other similarities, there are several differences among these infections. The number of COVID-19 cases dramatically exceeds the cases for the other epidemics, and COVID-19 is the only one to cause a worldwide pandemic. Notably, this, once an insignificant and benign family of viruses, the coronavirus, has now generated three fatal epidemics in the last two decades, showing the alert importance to this class of viruses. This will be a long-term challenge, and we cannot yet predict when the next coronavirus outbreak will occur. Therefore, more research, testing and development of better plans will be required to handle such pandemics in order to be better protected when they emerge in other mutants. 


\section{Acknowledgement}

Funding and laboratory facilities were provided by the Air Pollution Department and Chemistry of Natural and Microbial Products Department of the National Research Centre, Egypt that are gratefully acknowledged.

\section{References}

Abdi, M. (2020). Coronavirus disease 2019 (COVID-19) outbreak in Iran: Actions and problems. Infection Control \& Hospital Epidemiology. https://doi.org/10.1017/ice.2020.86

Adhikari, S. P., Meng, S., Wu, Y. J., Mao, Y. P., Ye, R. X., Wang, Q. Z., ... Raat H. (2020). Epidemiology, causes, clinical manifestation and diagnosis, prevention and control of coronavirus disease (COVID-19) during the early outbreak period: A scoping review. Infect. Dis Poverty 9, 29. https://doi.org/10.1186/s40249-020-00646-X

Ai, T., Yang, Z., Hou, H., Zhan, C., Chen, C., Lv, W., ... Xia, L. (2020). Correlation of chest CT and RT-PCR testing in coronavirus disease 2019 (COVID-19) in China: A report of 1014 cases. Radiology. https://doi.org/10.1148/radiol.2020200642

Amirian E. S. (2020). Potential fecal transmission of SARS-CoV-2: Current evidence and implications for public health. International Journal of Infectious Diseases, 95, 363-370. https://doi.org/10.1016/j.ijid.2020.04.057

Bendix A. (2020). A day-by-day breakdown of coronavirus symptoms shows how the disease, COVID-19, goes from bad to worse, Business Insider.

CDC (2020). Centers for Disease Control and Prevention.

Chen, Y., Liu, Q., \& Guo, D. (2020). Emerging coronaviruses: Genome structure, replication, and pathogenesis. Journal of Medical Virology. https://doi.org/10.1002/jmv.26234

Cheng, V., Wong, S-C., Chen, J., Yip, C., Chuang, V., \& Tsang, O. (2020). Escalating infection control response to the rapidly evolving epidemiology of the Coronavirus disease 2019 (COVID-19) due to SARS-CoV-2 in Hong Kong. Infect Control Hosp Epidemiol. https://doi.org/10.1017/ice.2020.58

Dhand, R., \& Li, J. (2020). Coughs and Sneezes: Their Role in Transmission of Respiratory Viral Infections, Including SARS-CoV-2. Am J Respir Crit Care Med., 202(5), 651-659. https://doi.org/10.1164/rccm.202004-1263PP

Di Gennaro, F., Pizzol, D., Marotta, C., Antunes, M., Racalbuto, V., Veronese, N., \& Smith, L. (2020). Coronavirus Diseases (COVID-19) Current Status and Future Perspectives: A Narrative Review. Int J Environ Res Public Health., 17(8), 2690. https://doi.org/10.3390/ ijerph17082690

Fan, Y., Zhao, K., Shi, Z. L., \& Zhou, P. (2019). Bat Coronaviruses in China. Viruses, 11(3), 210. https://doi.org/10.3390/v11030210

Gao, M., Yang, L., Chen, X., Deng, Y., Yang, S., Xu, H., ...Gao, X. (2020). A study on infectivity of asymptomatic SARS-CoV-2 carriers. Respiratory Medicine, 169, 1-6. https://doi.org/10.1016/j.rmed.2020.106026 
Gorbalenya, A. E., Baker, S. C., Baric, R. S., de Groot, R. J., Drosten, C., \& Gulyaeva, A. A. (2020). Severe acute respiratory syndrome-related coronavirus: the species and its viruses - a statement of the Coronavirus Study Group. https://doi.org/10.1101/2020.02.07.937862

Lagier, J. C., Colson, P., Tissot, D. H., Salomon, J., Doudier, B., Aubry, C., ... Flores R. (2020). Testing the repatriated for SARS-Cov2: Should laboratory-based quarantine replace traditional quarantine? Travel Med. Infect. https://doi.org/10.1016/j.tmaid.2020.101624

Li, X., Song, Y., Wong, G., \& Cui, J. (2020). Bat origin of a new human coronavirus: there and back again. Sci China Life Sci, 63. https://doi.org/10.1007/s11427-020-1645-7

Li, Y., \& Xia, L. (2020). Coronavirus disease 2019 (COVID-19): Role of chest CT in diagnosis and management. AJR Am. J. Roentgenol., 1-7. https://doi.org/10.2214/AJR. 19.22691

Lippi, G., Simundic, A. M., \& Plebani, M. (2020). Potential preanalytical and analytical vulnerabilities in the laboratory diagnosis of coronavirus disease 2019 (COVID-19) Clin. Chem. Lab. Med. https://doi.org/10.1515/cclm-2020-0285

Liu, X., Feng, J., Zhang, Q., Guo, D., Zhang, L., Suo, T., ... Lan, K. (2020). Analytical comparisons of SARSCOV-2 detection by qRT-PCR and ddPCR with multiple primer/probe sets, Emerg. Microbes Infect., 9(1), 1175-1179. https://doi.org/10.1080/22221751.2020. 1772679

Liu, Y., Hu, G., Wang, Y., Zhao, X., Ji, F., Ren, W., ...Ding, Q. (2020). Functional and genetic analysis of viral receptor ACE2 orthologs reveals a broad potential host range of SARS-CoV-2. BioRxiv, 04.22.046565. https://doi.org/10.1101/2020.04.22.046565

Lu, R., Zhao, X., Li, J., Niu, P., Yang, B., Wu, H., ... Tan, W. (2020). Genomic characterisation and epidemiology of 2019 novel coronavirus: implications for virus origins and receptor binding. Lancet, 395, 565-574. https://doi.org/10.1016/S0140-6736(20)30251-8

Ong, S. W. X., Tan, Y. K., Chia, P. Y., Lee, T. H., \& Ng, O. T. (2020). Air, Surface Environmental, and Personal Protective Equipment Contamination by Severe Acute Respiratory Syndrome Coronavirus 2 (SARS-CoV-2) From a Symptomatic Patient. Journal of American Medical Association, 323(16). https://doi.org/10.1001/jama.2020.3227

Paho. (2020). Modes of transmission of virus causing COVID-19: implications for IPC precaution recommendations. Scientific brief, 2020.

Pandey, S. C., Pandea, V., Satia, D., Upreti, S., \& Samanta, M. (2020). Vaccination strategies to combat novel corona virus SARS-CoV-2. Life Sciences, 256, 117956. https://doi.org/10.1016/j.lfs.2020.117956

Pathak, S. K. (2020). Focus on uncommon symptoms of COVID-19: Potential reason for spread of infection. Diabetes Metab Syndr, 14(6), 1873-1874.

Pillaiyar, T., Meenakshisundaram, S., \& Manickam, M. (2020). Recent discovery and development of inhibitors targeting coronaviruses. Drug Discov Today. https://doi.org/10.1016/j.drudis.2020.01.015

Rodriguez-Morales, A. J., Bonilla-Aldana, D. K., Balbin-Ramon, G. J., Rabaan, A. A., Sah, R., ... Esposito, S. (2020). History is repeating itself: Probable zoonotic spillover as the cause of the 2019 novel Coronavirus Epidemic. Infez Med, 28(1), 3-5. 
Shereen, M. A., Khan, S., Kazmi, A., Bashir, N., \& Siddique, R. (2020). COVID-19 infection: Origin, transmission, and characteristics of human coronaviruses. Journal of Advanced Research, 24, 91-98. https://doi.org/10.1016/j.jare.2020.03.005

Tahamtan, A., \& Ardebili, A. (2020). Real-time RT-PCR in COVID-19 detection: issues affecting the results. Expert Rev. Mol. Diagn, 20(5), 453-454. https://doi.org/10.1080/14737159.2020.1757437

Temgoua, M. N., Endomba, F. T., Nkeck, J. R., Kenfack, G. U., Tochie, J. N., \& Essouma, M. (2020). Coronavirus Disease 2019 (COVID-19) as a Multi-Systemic Disease and its Impact in Low- and Middle-Income Countries (LMICs) SN. Comprehensive Clinical Medicine, 2, 1377-1387. https://doi.org/10.1007/s42399-020-00417-7

Wang, C., Horby, P. W., Hayden, F. G., \& Gao, G. F. (2020). A novel coronavirus outbreak of global health concern. Lancet, 395(10223), 470-3. https://doi.org/10.1016/S01406736(20)30185-9

Wang H., Wang, S., \& Yu, K. (2020). COVID-19 infection epidemic: The medical management strategies in Heilongjiang Province. China. Crit. Care 2020, 24, 107. https://doi.org/10.1186/s13054-020-2832-8

World Health Organization (WHO) (2020a). Coronavirus disease (COVID-2019) situationreports.

World Health Organization (WHO) (2020b). Covid 19 Infection.

World Health Organization (WHO) (2020c). Laboratory biosafety guidance related to coronavirusdisease2019(COVID-19).

World Health Organization (WHO) (2020d). Coronavirus disease (COVID-19) advice for thepublic.

World Health Organization (WHO) (2020e). Rational use of personal protective equipment for coronavirus disease 2019 (COVID-19).

Wu, C., Liu, Y., Yang, Y., Zhang, P., Zhong, W., Wang, Y., Q. ...Li, H. (2020). Analysis of therapeutic targets for SARS-CoV-2 and discovery of potential drugs by computational methods. Acta Pharm. Sin. B, 10, 766-788. https://doi.org/10.1016/j.apsb.2020.02.008

Xu, X., Chen, P., Wang, J., Feng, J., Zhou, H., Li, X., ... Hao, P. (2020). Evolution of the novel coronavirus from the ongoing Wuhan outbreak and modeling of its spike protein for risk of human transmission. Sci China Inf Sci, 63, 457-460. https://doi.org/10.1007/ s11427-020-1637-5

Yang, Y., Peng, F., Wang, R., Guan, K., Jiang, T., Xu, G., ... Chang C. (2020). The deadly coronaviruses: The 2003 SARS pandemic and the 2020 novel coronavirus epidemic in China. J. Autoimmun. https://doi.org/10.1016/j.jaut.2020.102434

Ye, Z-W., Yuan, S., Yuen, K-S., Fung, S-Y., Chan, C-P., \& Jin, D-Y. (2020). Zoonotic origins of human coronaviruses. International Journal of Biological Sciences, 16(10), 1686-1697. https://doi.org/10.7150/ijbs.45472

Zhang, L., Shen, F. M., Chen, F., \& Lin, Z. (2020). Origin and evolution of the 2019 novel coronavirus. Clin Infect Dis ciaa112. https://doi.org/10.1093/cid/ciaa112 


\section{Macrothink}

Zhao, J., Cui, W., \& Tian, B-P. (2020). The Potential Intermediate Hosts for SARS-CoV-2. Front. Microbiol, 11, 580137, 1-11.

Zhou, P., Yang, X. L., Wang, X. G., Hu, B., Zhang, L., Zhang, W., ...Shi, Z. L. (2020). A pneumonia outbreak associated with a new coronavirus of probable bat origin. Nature, 579 (7798), 270-273.

Zou, L., Ruan, F., \& Huang, M. (2020). SARS-CoV-2 viral load in upper respiratory specimens of infected patients. N. Engl. J. Med., 382(12), 1177-1179. https://doi.org/10.1056/ NEJMc2001737

\section{Copyright Disclaimer}

Copyright reserved by the author(s).

This article is an open-access article distributed under the terms and conditions of the Creative Commons Attribution license (http://creativecommons.org/licenses/by/4.0/). 